\title{
Efeito da redução da densidade energética de dietas sobre as características do ovo de codorna japonesa
}

\author{
Guilherme de Souza Moura ${ }^{1}$, Sergio Luiz de Toledo Barreto ${ }^{1}$, Eduardo Arruda Teixeira Lanna ${ }^{1}$ \\ ${ }^{1}$ Departamento de Zootecnia - Universidade Federal de Viçosa.
}

RESUMO - Objetivou-se avaliar os efeitos da redução da densidade energética da dieta sobre a qualidade de ovo de codornas japonesas, mantendo a mesma relação energia metabolizável (EM):nutrientes. Foram utilizadas 400 codornas japonesas dos 76 aos 160 dias de idade, distribuídas em delineamento inteiramente casualizado, com cinco tratamentos, 10 repetições e 8 aves por unidade experimental. Utilizaram-se cinco dietas com densidades energéticas distintas (2.900, 2.800, $2.700,2.600$ e $2.500 \mathrm{kcal}$ de EM/kg), mantendo constante a relação entre energia metabolizável e nutrientes da dieta, que continha $2.900 \mathrm{kcal}$ de EM/kg. As aves foram arraçoadas à vontade durante todo o período experimental. Houve diferença significativa apenas no consumo de ração e peso no específico de ovo. Para consumo de EM, PB e aminoácidos, peso do ovo, massa do ovo, peso da gema, porcentagem da gema, peso do albúmen, porcentagem do albúmen, peso da casca, porcentagem da casca, diâmetro do ovo e altura do ovo, não foram encontradas diferença significativas entre as dietas. Recomenda-se utilizar dietas com 2.800 e $2.900 \mathrm{kcal}$ de EM/kg, mantendo a mesma relação EM:nutrientes da dieta, quando o objetivo for qualidade de ovo.

Palavras-chave: coturnicultura, Coturnix coturnix japonica, energia metabolizável, nutrição de codornas, nutrientes

\section{Effect of energetic density reduction of diets on characteristics of Japanese quail eggs}

\begin{abstract}
The aim of this study was to evaluate the effects of reduction of energetic density of the diet on the quality of Japanese quail eggs, keeping the same metabolizable energy (ME):nutrients relationship. It was used 400 Japanese quails from 76 to 160 days of age, distributed in a complete random design, with five treatments, 10 replicates and 8 birds per experimental unity. It was used five diets with different energetic densities $(2,900 ; 2,800 ; 2,700 ; 2,600$; and 2,500 kcal ME/kg), keeping constant the relationship between metabolizable energy and nutrients of the diet, which had 2,900 kcal ME/kg. Diet was fed ad libitum during all the experimental period. There was a significant difference only on the ration intake and on the egg specific weight. It was not observed significant difference among diets for the following parameters: metabolizable energy intake, crude protein and amino acids, egg weight, egg mass, yolk weight, yolk percentage, albumen height, albumen percentage, shell weight, shell percentage, egg diameters and egg height. Diets with 2,800 and 2,900 kcal ME/kg, by keeping constant metabolizable energy:nutrients ratio, provide the same egg quality.
\end{abstract}

Key Words: Coturnix coturnix japonica, metabolizable energy, nutrients, quail nutrition, quail production

\section{Introdução}

O ovo de codorna é considerado uma ótima alternativa para a alimentação humana, pois apresenta, na sua composição, uma proteína de alto valor biológico, elevado índice de digestibilidade (Albino \& Barreto, 2003), além de vitaminas e minerais (Murakami et al., 1994).

Para que todo esse potencial nutritivo seja utilizado pelo homem, a produção de ovos tem que remunerar satisfatoriamente o produtor e, ao mesmo tempo, beneficiar economicamente o consumidor. Desta forma, a redução nos custos de produção é a via mais importante para incrementar o comércio. De acordo com Garcia et al. (2006), práticas de manejo, como melhorias na nutrição e nos aspectos sanitários, ambientais e genéticos afetam diretamente o desempenho e a qualidade dos ovos e, consequentemente, o custo.

Normalmente, nos sistemas de criação de aves, o consumo é regulado pela densidade energética da dieta e pela exigência nutricional, o que, consequentemente, afeta o desempenho e a qualidade dos ovos. No entanto, observa-se que à medida em que é elevada a energia da dieta, ocorre uma

Recebido em 29/8/2008 e aprovado em 2/6/2009.

Correspondências devem ser enviadas para: mouraguilherme@yahoo.com.br 
diminuição no consumo voluntário pelas aves (Baião \& Lara, 2005). De acordo com Mello et al. (2009), este consumo está associado à menor ingestão de aminoácidos e outros nutrientes, o que pode acarretar variações quantitativas e qualitativas na produção.

Em um experimento com codornas japonesas, Murakami et al. (1993) concluíram que dietas contendo 2.700 kcal de $\mathrm{EM} / \mathrm{kg}$ e $18 \%$ de $\mathrm{PB}$ proporcionaram melhor desempenho na fase de postura. No entanto, o nível de 19,66\% de PB promoveu melhor conversão alimentar por massa de ovo. Pinto et al. (2002) verificaram que os níveis de 2.850 kcal de $\mathrm{EM} / \mathrm{kg}$ e 22,4\% de PB foram os mais adequados para o máximo desempenho das aves, e a interação proteína $\times$ energia não influenciou os parâmetros de qualidade de ovo.

Normalmente, diante desses resultados e de outros dados encontrados na literatura, a relação EM:PB para melhor desempenho e qualidade de ovos de codornas varia de 125 a 150:1, como base para cálculo de EM, PB e outros nutrientes. Desse modo, é importante ajustar o perfil de aminoácidos e outros nutrientes à densidade energética, ou seja, a quantidade de ração ingerida deve satisfazer nutricionalmente à mantença, além de aumentar a produtividade.

Assim, objetivou-se avaliar a qualidade de ovos de codornas japonesas submetidas a dietas com redução da densidade energética, mantendo constante a relação energia metabolizável(EM):nutrientes.

\section{Material e Métodos}

O experimento foi realizado no setor de avicultura do Departamento de Zootecnia do Centro de Ciências Agrárias da Universidade Federal de Viçosa, Minas Gerais, no período de agosto de 2005 a fevereiro de 2006. Foram utilizadas 400 codornas (Coturnix coturnix japonica) provenientes da Granja Fujikura (Suzano - São Paulo).

Antes do início da postura, as aves foram pesadas individualmente e alojadas em gaiolas de arame galvanizado, com as dimensões de $100 \times 23 \times 20 \mathrm{~cm}$ (comprimento $\times$ largura $\times$ altura), dispostas em três andares, montadas em esquema de escada. Cada gaiola foi subdividida em duas repartições iguais de $50 \mathrm{~cm}$, com capacidade para 10 aves, fornecendo uma área de $115 \mathrm{~cm}^{2} /$ ave. Sobre o piso de cimento, abaixo das gaiolas, foi colocada uma camada de maravalha para absorver o excesso de umidade das excretas.

O experimento foi conduzido dos 76 dias aos 160 dias de idade das aves, cujo peso inicial médio foi de $155 \pm 15,5$ g.
O manejo diário consistiu em recolher e contabilizar os ovos, fornecer ração, limpar os bebedouros e os aparadores de ovos e realizar leitura das temperaturas e umidade relativa do ar (UR). As temperaturas $\left({ }^{\circ} \mathrm{C}\right)$ e a UR (\%) foram monitoradas todos os dias do experimento, às $16 \mathrm{~h}$, por meio de termômetros de máxima e mínima e de bulbo seco e úmido, posicionados no corredor, entre as baterias de gaiolas.

O programa de iluminação teve início por volta do $45^{\circ}$ dia de idade das aves, com fornecimento inicial de 14 horas de luz diária, e com aumentos semanais de 30 minutos, até que se atingisse 17 horas de luz diária, permanecendo nessa quantidade até o término do período experimental. Esse fornecimento de luz foi controlado por um relógio automático (timer), que permitiu o acender e o apagar das luzes durante o período da noite e da madrugada, conforme o procedimento adotado nas granjas comerciais.

As exigências nutricionais utilizadas para a formulação das dietas das aves foram baseadas nas recomendações preconizadas pelo NRC (1994), exceto para as exigências de lisina, metionina+cistina (met + cis), treonina e cálcio. As exigências de lisina e de met + cis foram baseadas nas recomendações de Pinto et al. (2003). As exigências de cálcio e de treonina foram baseadas segundo Barreto et al. (2007) e Umigi et al. (2006), respectivamente.

O delineamento experimental foi inteiramente casualizado, com cinco tratamentos, 10 repetições e oito aves por unidade experimental. Para atender ao objetivo proposto, foram formuladas cinco dietas. Em cada tratamento, foi mantida a mesma relação entre a EM e os nutrientes da dieta que continha $2.900 \mathrm{kcal}$ de EM/kg. Essa relação foi baseada nos níveis recomendados pelo NRC, exceto para lisina, metionina+cistina (Pinto et al., 2003), cálcio (Barreto et al., 2007) e treonina (Umigi et al., 2006). Essas dietas foram à base de milho, de farelo de soja e de farelo de trigo (Tabela 1 ).

Os resultados obtidos foram submetidos à análise de variância e para comparação entre as médias, adotou-se o teste de Student Newman Keuls (SNK). Todas as análises foram efetuadas por intermédio do programa SAEG Sistemas para Análises Estatísticas e Genéticas-UFV (2004).

Os parâmetros avaliados foram: consumo de ração, de energia metabolizável (EM), de proteína bruta (PB) e dos aminoácidos suplementados; produção de ovos, peso médio dos ovos, massa dos ovos, peso e percentagem da gema, do albúmen e da casca, gravidade específica, altura e diâmetro médio dos ovos. 
Tabela 1 - Composição das dietas experimentais para codornas japonesas na fase de postura (na matéria natural)

\begin{tabular}{|c|c|c|c|c|c|}
\hline \multirow[t]{2}{*}{ Ingrediente } & \multicolumn{5}{|c|}{ Nível de energia metabolizável (kcal/kg) } \\
\hline & 2.900 & 2.800 & 2.700 & 2.600 & 2.500 \\
\hline Milho moído & 45,13 & 46,18 & 47,25 & 48,27 & 49,32 \\
\hline Farelo de soja & 33,87 & 31,82 & 29,75 & 27,73 & 25,68 \\
\hline Farelo de trigo & 6,00 & 7,00 & 8,00 & 9,00 & 10,00 \\
\hline Óleo vegetal & 5,70 & 4,47 & 3,25 & 2,03 & 0,80 \\
\hline Calcário & 6,75 & 6,55 & 6,35 & 6,15 & 5,93 \\
\hline Fosfato bicálcico & 1,26 & 1,19 & 1,12 & 1,06 & 0,99 \\
\hline Sal & 0,34 & 0,32 & 0,31 & 0,30 & 0,29 \\
\hline Areia lavada (inerte) & 0,167 & 1,706 & 3,213 & 4,723 & 6,262 \\
\hline DL-metionina $99 \%$ & 0,350 & 0,333 & 0,317 & 0,301 & 0,285 \\
\hline L-lisina HCL 78\% & 0,167 & 0,176 & 0,186 & 0,193 & 0,201 \\
\hline L-treonina $98 \%$ & 0,056 & 0,057 & 0,058 & 0,059 & 0,060 \\
\hline Cloreto de colina (60\%) & 0,040 & 0,039 & 0,038 & 0,037 & 0,036 \\
\hline Mistura mineral ${ }^{1}$ & 0,050 & 0,048 & 0,046 & 0,044 & 0,042 \\
\hline Mistura vitamínica ${ }^{2}$ & 0,100 & 0,097 & 0,094 & 0,091 & 0,088 \\
\hline Butil-hidroxi-tolueno ${ }^{3}$ & 0,010 & 0,010 & 0,010 & 0,010 & 0,010 \\
\hline Avilamicina $10 \%$ & 0,0100 & 0,009 & 0,008 & 0,007 & 0,006 \\
\hline \multicolumn{6}{|l|}{ Composição nutricional calculada } \\
\hline Energia metabolizável (kcal/kg) & 2.900 & 2.800 & 2.700 & 2.600 & 2.500 \\
\hline Proteína (\%) & 20,00 & 19,31 & 18,62 & 17,93 & 17,24 \\
\hline Lisina total $(\%)$ & 1,215 & 1,173 & 1,132 & 1,090 & 1,048 \\
\hline Lisina digestível (\%) & 1,117 & 1,078 & 1,040 & 1,001 & 0,963 \\
\hline Metionina + cistina total (\%) & 0,974 & 0,947 & 0,914 & 0,876 & 0,852 \\
\hline Metionina + cistina digestível (\%) & 0,894 & 0,863 & 0,832 & 0,801 & 0,771 \\
\hline Treonina total (\%) & 0,835 & 0,800 & 0,778 & 0,746 & 0,713 \\
\hline Treonina digestível (\%) & 0,730 & 0,700 & 0,680 & 0,650 & 0,630 \\
\hline Fibra bruta (\%) & 3,19 & 3,20 & 3,20 & 3,20 & 3,21 \\
\hline Cálcio (\%) & 3,00 & 2,90 & 2,80 & 2,70 & 2,60 \\
\hline Fósforo disponível (\%) & 0,3500 & 0,3380 & 0,3259 & 0,3138 & 0,3018 \\
\hline Sódio (\%) & 0,1500 & 0,1448 & 0,1396 & 0,1340 & 0,1290 \\
\hline
\end{tabular}

${ }^{1}$ Composição/kg: vit. A - 12.000 .000 U.I.; vit. $\mathrm{D}_{3}$ - 3.600 .000 U.I.; vit. E - 3.500 U.I.; vit $\mathrm{B}_{1}$ - 2.500 mg; vit. $\mathrm{B}_{2}$ - 8.000 mg; vit. $\mathrm{B}_{6}$ - 5.000 mg; ácido pantotênico - 12.000 mg; biotina - $200 \mathrm{mg}$; vit. K - $3.000 \mathrm{mg}$; ácido fólico - $1.500 \mathrm{mg}$; ácido nicotínico - 40.000 mg; vit. B 12 - 20.000 mcg; selênio - 150 mg; veículo q.s.p. - 1.00 g.

${ }^{2}$ Composição/kg: manganês - 160 g; ferro - 100 g; zinco - 100 g; cobre - 20 g; cobalto - 2 g; iodo - 2 g; excipiente q.s.p. - 1.000 g.

3 Butil-hidróxi-tolueno (antioxidante).

\section{Resultados e Discussão}

Durante o período experimental, as médias das temperaturas $\left({ }^{\circ} \mathrm{C}\right)$ mínima e máxima, e a umidade relativa do ar (\%), medidas no interior do aviário, foram de 20,0; 28,8 e 88,8, respectivamente.

Apenas a densidade energética da dieta teve efeito significativo sobre os valores médios de consumo e peso específico de ovo $(\mathrm{p}<0,01)$. Para os demais parâmetros, não houve efeito significativo ( $>>0,05)$ (Tabela 2$)$.

O consumo de ração pelas codornas foi afetado $(p<0,05)$ pela densidade energética das dietas. Ao reduzir de 2900 para $2500 \mathrm{kcal}$ de EM/kg de dieta, houve aumento de 2,4 g/ave/dia. Esse resultado corrobora com Angulo et al. (1993) que observaram aumento no consumo de ração em codornas japonesas de 0 aos 33 dias de idade, reduzindo o nível energético de 3.200 para $3.000 \mathrm{kcal}$ de EM/kg de dieta.

Também foi observado, por Pinto et al. (2002) e Freitas et al. (2005), aumento linear do consumo de ração quando reduzido o nível energético de dietas para codornas japonesas. Com isso, pode-se inferir que as codornas apresentam comportamento alimentar semelhante ao de galinhas poedeiras, que ajustam o consumo de ração em função do nível de energia da dieta (Murakami et al., 1993; Garcia et al., 2006; Pinto et al. 2002).

O consumo diário de energia metabolizável não teve efeito $(p>0,05)$ das dietas. Em termos de valores absolutos, as aves mantiveram o consumo de EM próximo em relação às cinco dietas, variando entre 69,7 e 66,1 kcal de EM/ave/dia. Yamane et al. (1980) e NRC (1994) relataram que o consumo diário de energia de codornas japonesas para melhor desempenho e qualidade de ovos deve ficar entre $63 \mathrm{e}$ $75 \mathrm{kcal} / \mathrm{ave} / \mathrm{dia}$. Avaliando vários níveis de EM para codornas japonesas, Freitas et al (2005) observaram ingestão média de $66 \mathrm{kcal} /$ ave/dia entre os tratamentos. Os resultados de todos estes estudos confirmam que, como em outras espécies de aves, as codornas japonesas também se alimentam para satisfazer a exigência de energia.

Também não foi encontrada diferença significativa $(p>0,05)$ entre os tratamentos para consumo de proteína bruta e de aminoácidos. As codornas mantiveram praticamente a mesma ingestão de EM, mas, com a correção 
Tabela 2 - Desempenho de codornas japonesas alimentadas com dietas formuladas com quatro densidades energéticas

\begin{tabular}{|c|c|c|c|c|c|c|}
\hline & \multicolumn{5}{|c|}{ Dieta } & \multirow[t]{2}{*}{$\mathrm{CV}(\%)^{*}$} \\
\hline & 2.900 & 2.800 & 2.700 & 2.600 & 2.500 & \\
\hline Consumo de ração (g/ave/dia)** & $24,6 a$ & $25,2 \mathrm{ab}$ & $25,4 \mathrm{abc}$ & $26,7 \mathrm{bc}$ & $27,0 \mathrm{c}$ & 5,047 \\
\hline Consumo de energia metabolizável (kcal/ave/dia) & 71,3 & 70,6 & 68,6 & 69,4 & 67,5 & 4,882 \\
\hline Consumo de proteína bruta (g/ave/dia) & 4,92 & 4,87 & 4,73 & 4,79 & 4,65 & 4,842 \\
\hline Consumo de lisina total (mg/ave/dia) & 298,9 & 297,9 & 287,5 & 291,0 & 283,8 & 4,824 \\
\hline Consumo de lisina digestível (mg/ave/dia) & 274,8 & 271,2 & 264,4 & 267,1 & 258,2 & 4,816 \\
\hline Consumo de metionina+cistina digestível (mg/ave/dia) & 219,9 & 217,1 & 211,6 & 213,7 & 205,7 & 4,843 \\
\hline Produção de ovos (\%/ave/dia) & 93,9 & 92,9 & 88,4 & 89,1 & 85,9 & 6,950 \\
\hline Peso dos ovos (g) & 12,25 & 12,34 & 12,18 & 12,31 & 12,11 & 2,376 \\
\hline Massa de ovos (g/ave/dia) & 11,41 & 11,42 & 10,97 & 11,09 & 11,17 & 9,769 \\
\hline Peso de gema (g) & 4,00 & 4,07 & 3,95 & 4,07 & 3,95 & 2,825 \\
\hline \%gema & 33,14 & 33,32 & 32,90 & 33,63 & 33,03 & 2,125 \\
\hline Peso de albúmen (g) & 7,12 & 7,20 & 7,12 & 7,10 & 7,09 & 2,485 \\
\hline \%albúmen & 58,94 & 58,97 & 59,32 & 58,58 & 59,25 & 1,308 \\
\hline$\%$ casca & 7,93 & 7,71 & 7,79 & 7,79 & 7,72 & 2,366 \\
\hline Gravidade específica $\left(\mathrm{g} / \mathrm{cm}^{3}\right)^{* * *}$ & $1,074 \mathrm{a}$ & $1,073 \mathrm{ab}$ & $1,073 \mathrm{ab}$ & $1,073 \mathrm{ab}$ & $1,071 \mathrm{~b}$ & 1,817 \\
\hline Diâmetro dos ovos (mm) & 25,65 & 25,69 & 25,56 & 25,64 & 25,51 & 0,913 \\
\hline Altura dos ovos (mm) & 32,62 & 32,65 & 32,52 & 32,56 & 32,31 & 1,070 \\
\hline
\end{tabular}

*CV (\%) - Coeficiente de variação. **Diferença significativa $(\mathrm{P}<0,05)$ pelo teste de SNK. *** Diferença significativa $(\mathrm{P}<0,01)$ pelo teste $\mathrm{SNK}$.

dos níveis proteicos e de aminoácidos nas dietas experimentais, o consumo destes foi corrigido. Belo et al. (2000) e Freitas et al. (2005) encontraram um maior consumo de PB nas dietas que continham 2.600 e $2.585 \mathrm{kcal}$ de EM/kg, respectivamente. Esses resultados contraditórios aconteceram, provavelmente, pelo fato de as codornas se alimentarem para satisfazer o nível de energia, aumentando, assim, a ingestão de proteína. No entanto, os autores não mantiveram as mesmas relações EM : PB e EM:aminoácidos entre os tratamentos, o que reduziu a ingestão proteica nos níveis de energia mais elevados.

A estimativa da exigência de lisina para codornas foi 7\% e 15\% maior do que o nível recomendado pelo NRC (1994), considerando que as dietas continham $20 \%$ e $23 \%$ de PB, respectivamente, e $2.900 \mathrm{kcal}$ de EM (Ribeiro et al., 2003). Semelhante ao ocorrido em outras espécies, a exigência quantitativa de lisina para codornas também aumenta com o nível de proteína bruta da ração (Morris et al., 1987; Rose \& Uddin, 1988). Porém, neste presente experimento, a correção entre os tratamentos na relação entre a EM e o nível de lisina na dieta foi o fator que mais contribuiu para aumentar o consumo de lisina.

Não foi observado influência $(\mathrm{P}>0,05)$ da densidade energética das dietas sobre a produção de ovos. Apesar deste resultado, as codornas alimentadas com a dieta que continha $2.900 \mathrm{kcal}$ de EM/kg produziram, em valores absolutos, 9,31\% mais ovos do que as codornas alimentadas com o nível mais baixo de energia metabolizável. A menor quantidade de óleo de soja na dieta com $2.500 \mathrm{kcal}$ provavelmente aumentou o incremento calórico. Com isso, houve redução na energia líquida, o que afetou negativamente a produção de ovos. Ao contrário, Cordeiro et al. (2003) observaram aumento na produção de ovos com a redução da densidade energética, mantendo o nível proteico fixo. Esse resultado pode ser explicado pelo fato de que os autores não mantiveram a mesma relação energia metabolizável:proteína bruta entre os tratamentos, o que promoveu um maior consumo de proteína bruta nas dietas de menor energia, refletindo na produção.

Para peso e massa de ovo, não foi observado diferença significativa $(p>0,05)$ entre os tratamentos. O consumo de lisina e dos outros nutrientes foi muito próximo entre os tratamentos, dando sustentabilidade similar à formação do ovo. Isso indica que qualquer uma das dietas utilizadas no experimento foi eficiente para estes parâmetros. Perly (1979), Murakami \& Furlan (2002) e Pinto et al. (2002) mencionaram que o peso e a massa de ovo são influenciados pela ingestão diária de proteína em poedeiras, com objetivo de garantir suas exigências em aminoácidos. Para a produção de ovos maiores, as codornas devem ingerir maior quantidade de proteína na dieta (Soares et al., 2003). Freitas et al. (2005) observaram aumento médio de $0,001 \mathrm{~g}$ no peso do ovo para cada Kcal de redução na energia da dieta.

Quanto à massa de ovo, estes autores também observaram um aumento linear de 7,2\% quando se reduziu de 2885 para $2585 \mathrm{kcal}$ de EM/kg de dieta. Segundo os autores, isso ocorreu devido ao maior consumo de ração à medida que se reduziu a EM, ocasionando, consequentemente, maior ingestão de aminoácidos. Stringhini et al. (1995), Belo et al. (2000) e Barreto et al. (2007) também 
obtiveram efeito linear crescente para peso de ovo com a redução da densidade energética.

O peso e a percentagem de gema, de albúmen e de casca não foram influenciados ( $\mathrm{p}>0,05)$ pelos tratamentos. A correção dos nutrientes a cada nível de EM das dietas e o aumento do consumo voluntário de ração, à medida que se reduziu a densidade energética, foi suficiente para atender o peso médio da gema, albúmen e casca em todos os tratamentos. Diferenças significativas $(\mathrm{P}>0,05)$ para peso e percentagem de gema também não foram encontrados por Costa et al. (2004), ao avaliarem dietas com níveis de 2.700, 2.800 e $2.900 \mathrm{kcal}$ de EM/kg e 17,5\% de PB em galinhas poedeiras.

Móri et al. (2005) avaliaram a qualidade do ovo de quatro grupos genéticos de codornas europeias alimentadas com a mesma dieta contendo $2.900 \mathrm{kcal}$ de EM/kg e 20\% de $\mathrm{PB}$. Não houve influência $(\mathrm{P}>0,05)$ do grupo genético com relação ao peso e percentagem de gema.

Os dados do presente trabalho e dos supracitados anteriormente relacionados à gema sugerem que codornas e galinhas poedeiras normalmente não sofrem influência da densidade energética na formação da gema, ou seja, a percentagem de gema produzida tem valores próximos a $30 \%$ do peso do ovo.

Para qualidade de albúmen, resultados contraditórios foram encontrados por Barreto et al. (2007), que observaram redução significativa $(\mathrm{p}<0,01)$ no peso do albúmen com o aumento da EM da dieta para codornas europeias. Os autores justificaram que, provavelmente, a não correção da lisina e dos outros nutrientes em relação à EM da dieta fizeram com que houvesse maior disponibilidade de nutrientes necessários à formação do ovo.

Quanto à qualidade da casca, a correção dos níveis de calcário, fosfato bicálcico, suplemento vitamínico e mineral, a cada nível energético, somado ao consumo voluntário, supriu a produção de casca em todos os tratamentos sem afetar ( $p>0,05)$ o seu peso e a sua percentagem.

Resultados semelhantes foram encontrados por Belo et al. (2000) para peso e percentagem, quando codornas japonesas foram submetidas a dietas com 2.585 a $2.885 \mathrm{kcal}$ de EM/kg. No entanto, as dietas fornecidas não foram corrigidas a cada nível de energia, o que também não alterou a qualidade da casca. Ao contrário, Murakami et al. (1993) observaram redução do peso e da percentagem média da casca ao elevar a densidade energética em dietas para codornas japonesas. A possível causa desse resultado foi a diminuição do peso do ovo com o aumento do nível de EM, pois existe uma relação inversa entre o peso do ovo e a percentagem da casca. Como todas as dietas possuíam os mesmos níveis de calcário, fosfato bicálcico, suplemento vitamínico e mineral, os níveis mais altos de EM reduziram o consumo da ração, diminuindo também a ingestão destes ingredientes. Isso ocasionou piora na qualidade da casca, considerando que a mobilização do cálcio para a produção da casca foi a mesma para todas as dietas. Esse resultado também foi observado no trabalho de Costa et al. (2004), em galinhas poedeiras, no qual o aumento da EM reduziu o peso e a percentagem de casca.

Em relação à gravidade específica, houve relevante diferença $(p<0,01)$ entre os tratamentos. Embora não tenham sido encontradas diferenças significativas quanto ao peso e à percentagem de casca, o maior peso de ovo, em termos absolutos, observado nas dietas de 2.900 a $2.600 \mathrm{kcal}$ de $\mathrm{EM} / \mathrm{kg}$, provavelmente afetou a gravidade específica.

Hempe et al. (1988) relataram que a gravidade específica dos ovos apresenta relação direta com o percentual de casca, podendo ser utilizado como método indireto na determinação da qualidade desta. Estudando a relação entre a percentagem de ovos quebrados e a gravidade específica, Abdallah et al. (1993) observaram que a percentagem de ovos trincados decresce com o aumento da gravidade específica, resultando em uma correlação negativa $(r=-0,96)$ entre as variáveis. De acordo com os autores, para cada aumento de $0,001 \mathrm{~g} / \mathrm{cm}^{3}$ na gravidade específica, ocorreu redução de 1,266\% na porcentagem de ovos quebrados.

Não houve diferença significativa $(\mathrm{P}>0,05)$ para diâmetro e altura dos ovos. Como a densidade energética não alterou os constituintes dos ovos entre os tratamentos, as dimensões dos ovos também não foram afetadas.

\section{Conclusões}

Recomenda-se utilizar dietas com 2.800 e $2.900 \mathrm{kcal}$ de EM/kg, mantendo a mesma relação EM:nutrientes da dieta, quando o objetivo for qualidade de ovo.

\section{Agradecimentos}

À Fundação de Amparo à Pesquisa do Estado de Minas Gerais (FAPEMIG) e ao Conselho Nacional de Desenvolvimento Científico e Tecnológico (CNPq), pelo apoio concedido.

\section{Referências}

ABDALLAH, A.G.; HARMS, R.H.; EL-HUSSEINY, O. Various methods of measuring shell quality in relation to percentage of cracked eggs. Poultry Science, v.72, p.2038-2043, 1993.

ALBINO, L.F.T.; BARRETO, S.L.T. Codornas: criação de codornas para produção de ovos e carne. Viçosa, MG: Aprenda Fácil, 2003. 289p. 
ANGULO, E.; BRUFAU, J.; MIQUEL, A. et al. Effect of diet density and pelleting on productive parameters of Japanese quail. Poultry Science, v.72, p.607-610, 1993.

BAIÃO, N.C.; LARA, L.J.C. Oil and fat in broiler nutrition. Revista Brasileira de Ciência Avícola, v.7, n.3, p. 129-141, 2005.

BARRETO, S.L.T.; PEREIRA, C.A.; UMIGI, R.T. et al. Determinação da exigência nutricional de cálcio de codornas japonesas na fase inicial do ciclo de postura. Revista Brasileira de Zootecnia, v.36, n.1, p.68-78, 2007.

BARRETO, S.L.T.; QUIRINO, B.J.S.; BRITO, C.O. et al. Níveis nutricionais de energia sobre o desempenho e qualidade de ovos de codornas européias na fase inicial de postura. Revista Brasileira de Zootecnia, v.36, n.1, p.86-93, 2007.

BELO, M.T.S.; COTTA, J.T.B.; OLIVEIRA, A.I.G. Níveis de energia metabolizável em rações de codornas japonesas (Coturnix coturnix japonica) na fase inicial de postura. Ciência Agrotécnica, v.24, n.3, p.782-793, 2000.

CORDEIRO, M.D.; SOARES, R.T.R.N.; AVILA, R.P. Níveis de energia metabolizável para codornas japonesas (Coturnix coturnix japonica) na fase inicial de postura. In: REUNIÃO ANUAL DA SOCIEDADE BRASILEIRA DE ZOOTECNIA, 40., 2003, Santa Maria. Anais... Santa Maria: Sociedade Brasileira de Zootecnia, 2003. p.187-194.

COSTA, F.G.P.; SOUSA, H.C.;.GOMES, A.V.C. et al. Níveis de proteína bruta e energia metabolizável na produção e qualidade dos ovos de poedeiras da linhagem Lohmann Brown. Ciência Agrotécnica, v.28, n.6,p.1421-1427, 2004.

FREITAS, A.C.; FUENTES, M.F.F.; FREITAS, E.R. et al. Efeito de níveis de proteína bruta e de energia metabolizável sobre o desempenho de codornas de postura. Revista Brasileira de Zootecnia, v.34, n.3, p.838-846, 2005.

GARCIA, A.R.; BATAL, A.B.; BAKERT, D.H. variations in the digestible lysine requirement of broiler chickens due to sex, performance parameters, rearing environment, and processing yield characteristics. Poultry Science, v.85, p.498-504, 2006.

HEMPE, J.K.; LAUXWN, R.C.; SAVAGE, J.E. Rapid determination of egg weight and specific gravity using a computerized datacollection system. Poultry Science, v.67, p.902-907, 1988.

MELLO, H.H.C.; GOMES, P.C.; ROSTAGNO, H.S. et al. Valores de energia metabolizável de alguns alimentos obtidos com aves de diferentes idades. Revista Brasileira de Zootecnia, v.39, n.5, p.863-868, 2009.

MÓRI, C.; GARCIA, E.A.; PAVAN, A.C. et al. Desempenho e qualidade dos ovos de codornas de quatro grupos genéticos. Revista Brasileira de Zootecnia, v.34, n.3, p.864-869, 2005.

MORRIS, T.R.; AL-AZZAWI, K.; GOUS, R.M. Effects of protein concentration on responses to dietary lysine by chicks. British Poultry Science, v.28, p.185-195, 1987.
MURAKAMI, A.E.; MORAES, V.M.B.; ARIKI, J. Níveis de proteína e energia em dietas de codornas Japonesas (Coturnix coturnix japonica) em postura. Revista Brasileira de Zootecnia, v.22, n.4, p.541-551, 1993.

MURAKAMI, A.E.; BARRIVIERA, V.A.; SCAPINELLO, C. et al. Efeito da temperatura e do período de armazenamento sobre a qualidade interna do ovo de codorna japonesa (Coturnix coturnix japonica) para consumo humano. Revista Unimar, v.16, suplemento 1, p.13-25,1994.

MURAKAMI, A.E.; FURLAN, A.C. Pesquisa na nutrição e alimentação de codornas em postura no Brasil. In: Simpósio Internacional de Coturnicultura, 2002, Lavras. Anais... Lavras: Universidade federal de Lavras, 2002. p.113-120.

NATIONAL RESERCH COUNCIL - NRC. Nutrient requirements of poultry. 9.ed. Washington: National Academy of Sciences, 1994. 155p.

PERLY, L. Correlação entre índice morfológico, peso do ovo e peso vivo ao final da fase de crescimento em codornas domésticas (Coturnix coturnix coturnix). Revista do Setor de Ciências Agrárias, v.1, n.1, p.41-53, 1979.

PINTO, R.; FERREIRA, A.S.; ALBINO, L.F.T. Níveis de proteína e energia para codornas japonesas em postura. Revista Brasileira de Zootecnia, v.32, n.5, p.1761-1770, 2002.

PINTO, R.; FERREIRA, A.S.; DONZELE, J.L. et al. Exigência de lisina para codornas japonesas em postura. Revista Brasileira de Zootecnia, v.32, n.5, p.1182-1189, 2003.

RIBEIRO, M.L.G.; SILVA, J.H.V.; DANTAS, M.O. et al. Exigências nutricionais de lisina para codornas durante a fase de postura, em função do nível de proteína da ração. Revista Brasileira de Zootecnia, v.32, n.1, p.156-161, 2003.

ROSE, S.P.; UDDIN, M.S. Effect of temperature on the response of broiler chickens to dietary lysine balance. British Poultry Science, v.39, p.36-37, 1988.

SOARES, R.T.R.N.; FONSECA, J.B.; SANTOS, A.S.O. Protein requeriment of japanese quail (Coturnix coturnix japonica) during rearing and laying periods. Revista Brasileira de Ciência Avícola, v.5, n.2, 2003.

STRINGHINI, J.H.; CAFÉ, M.B.; MOGYCA, N.S. Níveis de energia metabolizável e metionina para codornas japonesas em postura (Coturnix coturnix coturnix). In: Conferência Apinco de Ciência e Tecnologia Avícolas, 1995, Curitiba. Anais... Campinas: FACTA, 1995, p.125-126.

UMIGI, R.T.; BARRETO, S.L.T.; DONZELE, J.L. et al. Níveis de treonina digestível em dietas para codorna japonesa em postura. Revista Brasileira de Zootecnia, v.36, n.6, p.1868-1874, 2006.

UNIVERSIDADE FEDERAL DE VIÇOSA - UFV. Sistema de análises estatísticas e genéticas - SAEG . Versão 8.0. Viçosa, MG, 2000. 142p.

YAMANE, T.; ONO, K.; TANAKA, T. Energy requirement of laying Japanese quail. British Poultry Science, v.21, n.6, p.451, 1980. 